\title{
Experimental Study on Optimization of Polymer Preslug Viscosity of ASP Flooding in Interlayer Heterogeneous Well Group Artificial Sandstone Core
}

\author{
Qiji Sun $\mathbb{D}^{1,2}$ Kesen Yang, ${ }^{1,2}$ Guomin Xu $\mathbb{D}^{3}$, Shunde Yin $\mathbb{D}^{4}$, and Chunsheng Wang $\mathbb{D}^{1,2}$ \\ ${ }^{1}$ School of Petroleum Engineering, Northeast Petroleum University, Daqing 163318, China \\ ${ }^{2}$ Key Laboratory of Enhanced Oil Recovery(Northeast Petroleum University), Ministry of Education, Daqing 163318, China \\ ${ }^{3}$ PetroChina Daqing Oilfield Co. Ltd., Daqing 163318, China \\ ${ }^{4}$ Department of Civil and Environmental Engineering, University of Waterloo, Waterloo, ON, Canada N2L 3G1
}

Correspondence should be addressed to Qiji Sun; sunqiji@nepu.edu.cn, Guomin Xu; xuguomin@petrochina.com.cn, Shunde Yin; shunde.yin@uwaterloo.ca, and Chunsheng Wang; wangchunsheng@nepu.edu.cn

Received 22 June 2021; Revised 22 September 2021; Accepted 27 September 2021; Published 21 October 2021

Academic Editor: Zhenghe Liu

Copyright (C) 2021 Qiji Sun et al. This is an open access article distributed under the Creative Commons Attribution License, which permits unrestricted use, distribution, and reproduction in any medium, provided the original work is properly cited.

\begin{abstract}
An artificial sandstone core model of large well group of positive rhythmic heterogeneous reservoir was designed and made for the simulation of ASP flooding experiment in the moderate heterogeneous reservoir. The well layout of one injection and one production was employed for the core model, to simulate the influence of polymer preslugs with different viscosity on ASP flooding effect. The experimental results show that the injectability of the polymer preslug and the effect of relieving the conflict of remaining oil production in each layer are related to the viscosity of the system. In the heterogeneous core model with the coefficient of variation of 0.65 , under the constraint of the same amount of polymer agent, the ASP flooding effect of the $0.075 \mathrm{PV}, 60 \mathrm{mPa} \cdot \mathrm{s}$ polymer preslug was better than that of the $0.093 \mathrm{PV}, 40 \mathrm{mPa} \cdot \mathrm{s}$ and $0.064 \mathrm{PV}, 80 \mathrm{mPa} \cdot \mathrm{s}$ polymer preslugs. The change in the viscosity of the polymer preslug did not enable the ASP system to effectively exploit the lowpermeability layer though. As the viscosity increased, the pressure difference between injection and production increased; the remaining oil could be exploited effectively at the bottom of the high-permeability layer and the medium-permeability layer as well as the injection end of the medium-permeability layer. If the viscosity is too small, the high-permeability area cannot be effectively blocked by the injected chemical agent, and if the viscosity is too large, the injected chemical agent cannot produce good elastic displacement relationship, which will lead to ineffective chemical agent flow. Therefore, the polymer preslug viscosity of the ASP flooding system should be moderate, and cores with different heterogeneity should have a reasonable viscosity matching range.
\end{abstract}

\section{Introduction}

As a major oilfield in China, Daqing Oilfield has entered the stage of tertiary oil recovery with high water cut after 62 years of exploitation [1-3]. The development of conventional homogeneous high-permeability reservoirs using alkali/surfactant/polymer (hereinafter referred to as ASP) ternary compound chemical flooding system can enhance oil recovery by more than $20 \%$ for water flooding [4-6]. In recent years, due to the increasing cost of chemical agents and the application of ASP flooding in heterogeneous reservoirs, the injection mode of multislug chemical agent combination or the multislug alternate injection of chemical agents of different viscosity systems is adopted in the field test area to save costs $[7,8]$.

In low-permeability reservoirs with fractured development, Algharaib et al. [9] reduced the loss of alkali agents and the loss of surfactant adsorption in the ASP system by the injection of polymer preslugs and also proved that the polymer preslug can adjust the displacement profile, so that the ASP system can further enter areas that are not affected in the water flooding stage. For highly saline reservoirs, a 
large number of preflush slugs are required prior to chemical flooding to reduce the loss of chemical agents by highly saline water in the reservoir. Therefore, the use of various types of slugs before main agent injection can provide protection of chemical main agent [10-12]. Khan et al. carried out the alternate injection scheme of high-viscosity slug and low-viscosity slug [13]. The study shows that the alternate multislug injection enhanced oil recovery by more than $2 \%$ over single-slug injection and reduced polymer consumption by about $15 \%$. That is, multislug injection is conducive to enhancing oil recovery and saving the use of chemical agents. For areas with severely developed reservoir heterogeneity (medium heterogeneity: 0.5-0.7, strong heterogeneity: $>0.7$ ), the cost input of chemical flooding is more risky [14-16]. Therefore, polymer protection slugs are added before and after ASP main and secondary slugs, to ensure that the ASP slugs enter the remaining oil-rich area and avoid the dominant channel after water flooding [17, 18]. Hou et al. defined the critical displacement viscosity ratio (ratio of displacement fluid viscosity to crude oil viscosity) through a large number of laboratory experiments and studied the viscosity matching between heterogeneous reservoir and ASP system [19]. Shedid optimized the concentration and length of each ASP slug in low-permeability carbonate reservoirs and demonstrated the effectiveness of ASP flooding system in low-permeability carbonate reservoirs [20]. The results show that the higher the degree of reservoir heterogeneity, the higher the viscosity ratio of the optimal displacement fluid to reservoir fluid required for profile adjustment [21-23]. When the viscosity ratio of polymer system to underground crude oil reaches 3.0 or more, the polymer system has a stronger ability to expand the swept volume and improve the oil displacement efficiency [24-26].

In this paper, by taking the polymer preslug in the ASP multislug flooding system as the main research objective, the effect of preslugs with different polymer concentrations on chemical flooding recovery was mainly considered under the same agent cost (that is, the same amount of polymer). In this paper, the effect of polymer preslugs with different viscosity on the recovery factor of ASP flooding was investigated, with a particular focus on multislug ASP flooding in a three-layer heterogeneous large-scale well group made of artificial sandstone cores of different permeabilities. The optimal polymer preslug injection viscosity of the heterogeneous reservoir rich in remaining oil in Daqing Oilfield was investigated and demonstrated. At the same time, this paper discusses in detail the preparation of the artificial sandstone core model of large well group and the parts, component proportion, and manufacturing technology needed in the preparation process, which improves the quality of core processing and makes the core preparation process and details more scientific. With the development of oil fields, several projects have proposed the method of fracturing to tap more potential after ASP flooding [27, 28]. The simulation of the artificial sandstone core displacement experiment has gradually changed from the simple displacement method to the study of displacement method considering complex stress conditions and fracture conditions [29-31].

\section{Preparation of the Artificial Sandstone Core Model of Large Well Group}

The artificial sandstone core model of large well group was a cemented curing model, which was mainly composed of quartz sand and epoxy resin mixed in proportion and solidified after compaction by hydraulic press. The finished model is shown in Figure 1. The vertical heterogeneity of each layer in the core model was mainly controlled by the particle size of quartz sand and the amount of epoxy resin. The permeability variation range of cores with the same composition can be controlled within $20 \sim 50 \mathrm{mD}$ only by the size and duration of compaction pressure.

The purpose of establishing reservoir physical model is to make the oil saturation distribution in the model conform to the real underground situation, which is complicated and affected by many factors. In general, the physical model should be as close to the actual oilfield as possible in geometric conditions, physical conditions, boundary conditions, and initial conditions. Some of these conditions, such as model length, production pressure difference, and oil-water viscosity ratio, can be directly controlled and selected. However, it is relatively difficult to control the gas permeability of the artificial sandstone core model, and the core permeability should be consistent with the field permeability in the physical experiment. The main factors affecting the permeability of artificial cores are the particle size of sand, the intergranular porosity, and the amount of cementing agent. Therefore, before the physical experiment, a large number of artificial sandstone core models should be made for permeability testing so as to find the appropriate sand diameter ratio, compaction pressure and time, and the dosage of cementing agent. The results of a large number of artificial sandstone core production show that under the same compaction pressure and sand dosage, increasing the particle size of sands and reducing the dosage of cementing agent can keep the porosity unchanged and improve the gas permeability of the core. The artificial sandstone core model (shown in Figure 1) used the same porosity as the oilfield prototype, the same polymer solution, alkali, surfactant, and the same crude oil and remained geometrically similar in size. Model parameters for physical simulation calculated based on oilfield prototype parameters are shown in Table 1.

\section{Artificial Sandstone Core Making Method}

The artificial sandstone core model of large well group was $500 \mathrm{~mm}$ long, $500 \mathrm{~mm}$ wide, and $45 \mathrm{~mm}$ high. The vertical three layers had heterogeneous arrangement, with the high-permeability layer at the lower layer of the model, the medium-permeability layer at the middle layer, and the low-permeability layer at the upper layer. Electrode monitoring points, aluminum pressure monitoring points, and injection/production holes were arranged on the upper surface of the core, to monitor the change in internal resistivity of the core (the resistance values in cores are different with different water cut), the change in internal pressure of the core, and the saturation during the core flooding 


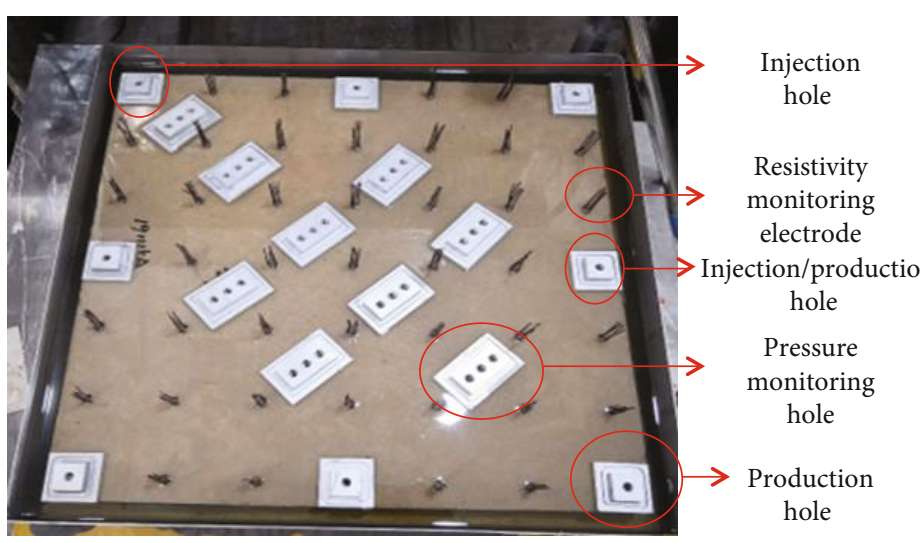

Figure 1: Artificial sandstone core model of large well group and main accessories.

TABLE 1: Comparison of prototype and model parameters.

\begin{tabular}{|c|c|c|c|c|}
\hline Similarity criteria & Attribute similarity & Purpose & $\begin{array}{l}\text { Physical model } \\
\text { values }\end{array}$ & $\begin{array}{c}\text { Field } \\
\text { values }\end{array}$ \\
\hline$\left(\frac{k z}{q_{I} \mu_{w}} \rho_{o} g h\right)_{m}=\left(\frac{k z}{q_{I} \mu_{w}} \rho_{o} g h\right)_{n}$ & $\begin{array}{l}\text { Ratio of gravity to } \\
\text { driving force }\end{array}$ & Determine the amount of model injection & $0.3 \mathrm{~mL} / \mathrm{min}$ & $30 \mathrm{~m}^{3} / \mathrm{d}$ \\
\hline$x_{D}=\frac{x_{m}}{x_{n}}$ & Geometric similarity & Determine the model size & $70.7 \mathrm{~cm}$ & $50 \mathrm{~m}$ \\
\hline$z_{D}=\frac{z_{m}}{z_{n}}$ & Geometric similarity & Determine the model thickness & $42 \mathrm{~cm}$ & $30 \mathrm{~m}$ \\
\hline$\left(\frac{k z \Delta P}{q_{I} \mu_{w}}\right)_{m}=\left(\frac{k z \Delta P}{q_{I} \mu_{w}}\right)_{n}$ & Dynamic similarity & $\begin{array}{l}\text { Determine the injection-production pressure } \\
\text { difference of the model }\end{array}$ & $0.2 \mathrm{MPa}$ & $15 \mathrm{MPa}$ \\
\hline$\Phi_{m}=\Phi_{n}$ & Consistent porosity & Determine the model porosity & $22 \%$ & $22 \%$ \\
\hline$\mu_{m}=\mu_{n}$ & $\begin{array}{l}\text { Consistent crude oil } \\
\text { viscosity }\end{array}$ & Determine the crude oil viscosity & $10 \mathrm{mPa} \cdot \mathrm{s}$ & $10 \mathrm{mPa} \cdot \mathrm{s}$ \\
\hline$k_{m}=k_{n}$ & $\begin{array}{l}\text { Consistent gas log } \\
\text { permeability }\end{array}$ & Determine the model average permeability & $500 \mathrm{mD}$ & $500 \mathrm{mD}$ \\
\hline
\end{tabular}

Subscript $m$ : model; subscript $n$ : oilfield prototype; $z$ : reservoir thickness, $\mathrm{m} ; h$ : reservoir depth, $\mathrm{m} ; \rho_{o}$ : oil-phase density, $\mathrm{kg} / \mathrm{m}^{3} ; k$ : gas permeability, $\mathrm{mD} ; \mu_{w}$ : water-phase viscosity, $\mathrm{mPa} \cdot \mathrm{s} ; q_{l}$ : the volume of water injected into the reservoir by the injection well per unit time, $\mathrm{m}^{3} / \mathrm{s} ; x_{D}$ : the similarity ratio of characteristic length; $x_{m}$ : the model length, $\mathrm{m} ; x_{n}$ : the field prototype length, $\mathrm{m} ; \Phi$ : porosity, $\% ; \Delta P$ : pressure difference between production and injection, $\mathrm{MPa} ; \%$; oil-phase viscosity, $\mathrm{mD} ; \mathrm{g}$ : acceleration of gravity, $\mathrm{m} / \mathrm{s}^{2}$.

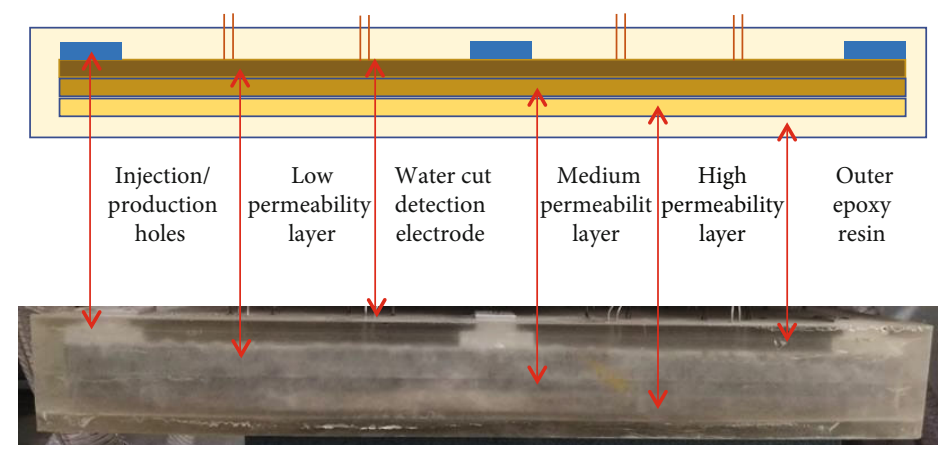

FIGURE 2: Side structure of the artificial sandstone core model of large well group.

experiment, respectively, as shown in Figure 2. A variety of injection and production methods can be simulated by the layout of injection and production holes. The well pattern in this paper was the diagonal layout, simulating the devel- opment mode of one injection and one production well. The vertical coefficient of variation of the model was 0.65 , and the gas permeability and making process of each layer are shown in Table 2. 


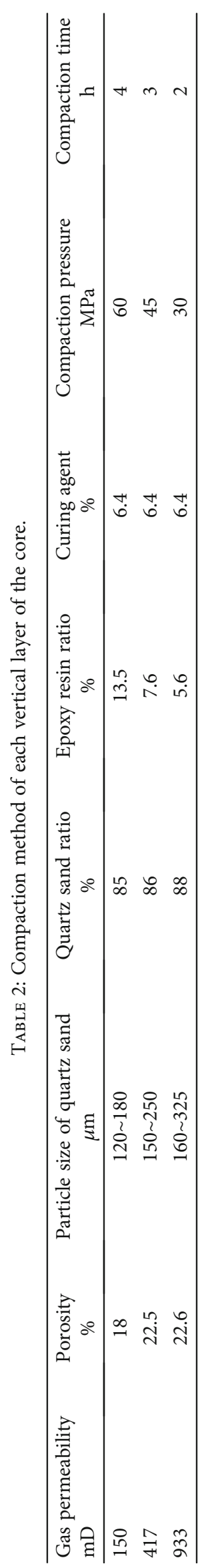




\section{Design and Making of Pressing Plate Mold and Related Accessories}

The pressing plate mold is a key technology to make the core physical model of well group with electrode and pressure holes. The pressing plate is mainly to distribute the downward pressure of the hydraulic press and acts directly on the cemented sand body to compact the sand body. In the previous model making process, the core is first compacted with a flat pressing plate without any reserved holes, then cemented, and drilled with monitoring holes of various functions. On the improved pressing plate, the orifice locations are drilled first for the monitoring resistor, pressure collecting hole, and production/injection fluid, and a cylindrical tube is inserted into the core to reserve holes before the core is pressed and cemented. Thus, the well location, electrode monitoring point and pressure probe hole can be made synchronously in the process of core compaction and cementing, so as to avoid the link of drilling and extending with drill tools after core compaction and cementing, reduce the damage to sand body after compaction and cementing, and keep physical properties such as porosity and permeability in the core unchanged. Compared with the model of postprocessed orifice, the one-step forming core physical model can withstand greater chemical displacement pressure.

The pressing plate was designed as $510 \mathrm{~mm}$ long, $510 \mathrm{~mm}$ wide, and $30 \mathrm{~mm}$ thick. A total of 8 injection/production holes were designed on the plate, each of which allows for the collection of injected and produced fluids as well as simulating water inflow, water retreat, and core oil saturation processes during the initial stage of the experiment. There were 41 groups of electrode monitoring points. Each group of electrode monitoring points included 3 pairs of 6 electrodes, with a spacing of $6 \mathrm{~mm}$ between each pair, which were, respectively, used to monitor the resistance change caused by the change of water cut in the highpermeability layer, medium-permeability layer, and lowpermeability layer. There were 9 groups of pressure monitoring points. Each group of pressure monitoring points included 3 pressure holes with a diameter of $4 \mathrm{~mm}$ and a spacing of $15 \mathrm{~mm}$ between each hole, which were, respectively, used to monitor the pressure changes in the highpermeability layer, medium-permeability layer, and lowpermeability layer. The details are shown in Figures 3 and 4 .

Pressure probe hole mould is shown in Figure 5. It is composed of upper and lower parts. The lower thin part is inserted into the core to prefabricate the orifice, while the upper thick end bears the downward pressure. The upper bearing cylinder had a diameter of $15 \mathrm{~mm}$ and a height of $30 \mathrm{~mm}$, while the lower insertion cylinder had a diameter of $3 \mathrm{~mm}$, and lengths of $37.5 \mathrm{~mm}, 52.5 \mathrm{~mm}$, and $67.5 \mathrm{~mm}$, respectively. The different length of the lower thin part of the pressure measuring point is mainly to cooperate with the pressing plate mold, so that it can be accurately inserted into different layers at different longitudinal depths of the core to accurately measure the fluid pressure of each layer.

The injection/production wellbore mould consists of upper and lower parts (as shown in Figure 6). It is mainly

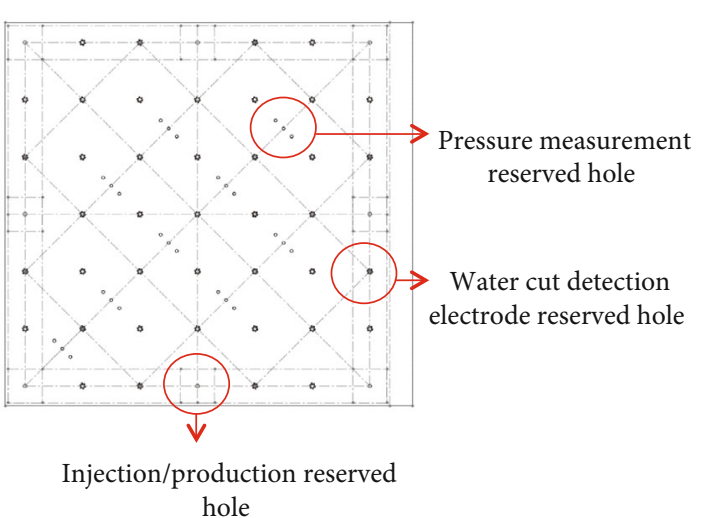

Figure 3: Design drawing of pressing plate mold.

used to form a cylindrical longitudinal flow channel in the core. The upper bearing cylinder had a diameter of $45 \mathrm{~mm}$ and a height of $30 \mathrm{~mm}$. The lower thin insertion end had a diameter of $3 \mathrm{~mm}$ and a length of $70 \mathrm{~mm}$. The wellbore mould and the pressure probe hole mould had the same upper cylinder part of $30 \mathrm{~mm}$, so that the pressure end is in the same horizontal plane once they are put in the pressing plate to keep the core pressing surface level.

Monitoring electrode wires were made of copper wires coated with insulating paint, and the exposed copper wire of the monitoring end monitored the resistance change caused by the change of water cut inside the core. Each electrode monitoring point had 3 pairs of electrodes, each of which was used to test water cut changes in a layer. If a single electrode is inserted directly into the core, the wire will bend, resulting in large error in the measured data $[11,16]$. Therefore, an integrated accessory for the electrode wire was designed and processed. Thus, 6 electrodes can be inserted simultaneously at different depths before the core is pressed and cemented. The electrode integrated accessory was designed as $6 \mathrm{~mm}$ in diameter and $10 \mathrm{~mm}$ in height. 6 semicircular grooves with a diameter of $1.5 \mathrm{~mm}$ were uniformly distributed on the circumferential surface (as shown in Figure 7(a)).

The grooves were used to place electrodes, and the electrodes were fastened with rubber rings to ensure flush tops. Then, electrodes of different lengths of $10 \mathrm{~cm}, 8.5 \mathrm{~cm}$, and $7 \mathrm{~cm}$ can be inserted into the specified depth, with the $10 \mathrm{~cm}$ electrode pair for monitoring the high-permeability layer, the $8.5 \mathrm{~cm}$ electrode pair for the mediumpermeability layer, and the $7 \mathrm{~cm}$ electrode pair for the lowpermeability layer. The assembled electrode wires are shown in Figure 7(b).

Quartz sand and epoxy resin corresponding to different permeability were mixed evenly and spread into the mold successively from low-permeability to high permeability. Then, the electrode assembly, wellbore mould, and pressure probe hole mould were inserted (as shown in Figure 8(a)). The flat plate was used to press the low-permeability layer, then the medium-permeability layer, and finally, the highpermeability layer, to ensure that the sand body is $1.5 \mathrm{~cm}$ thick after each layer is compacted. After compaction, the 


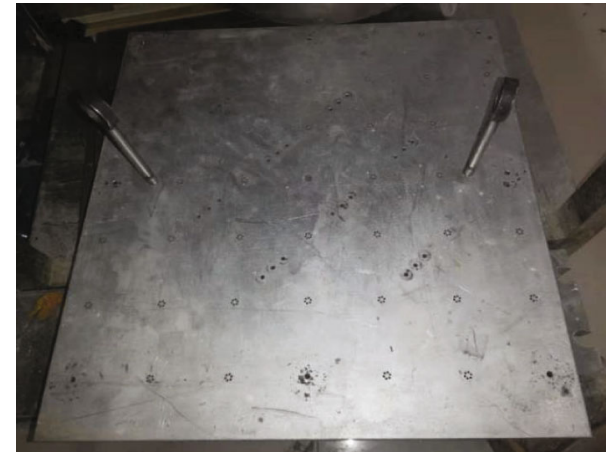

Figure 4: Picture of pressing plate mold.

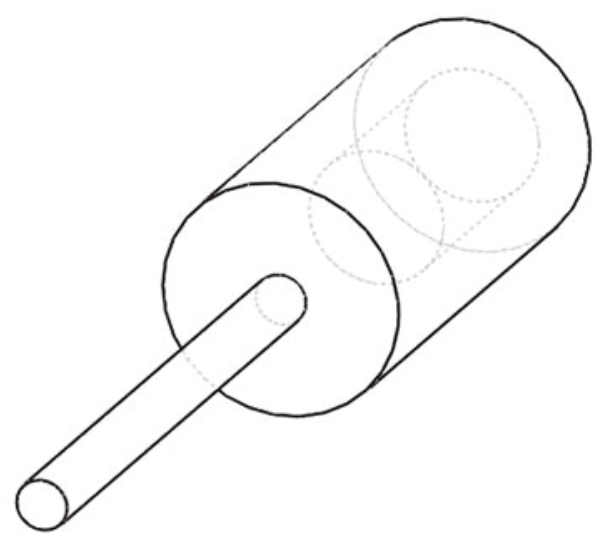

FiguRE 5: Schematic diagram of pressure probe hole mould.

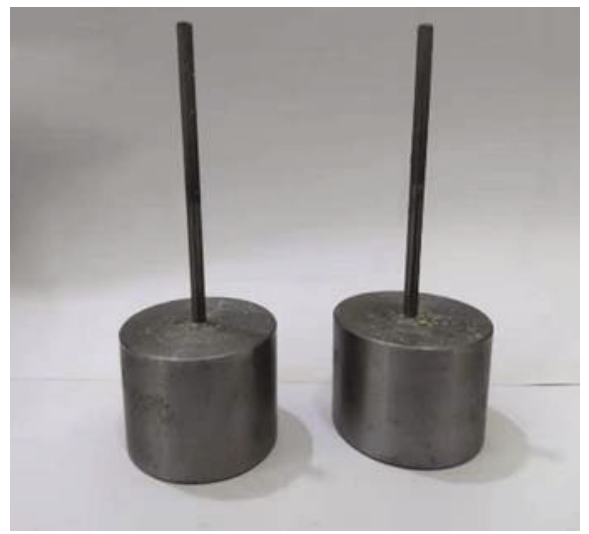

FIGURE 6: Wellbore mould.

accessories were removed to dry the core and obtain a core model not coated with epoxy resin (as shown in Figure 8(b)).

\section{Experiment Scheme}

The flooding scheme in this experiment: water flooding (water cut at the outlet stable at 98\%) + polymer preslug (fixed polymer dosage) + 0.3 PV ASP main slug + $0.2 \mathrm{PV}$ ASP secondary slug $+0.2 \mathrm{PV}$ subsequent polymer slug + $0.2 \mathrm{PV}$ subsequent water flooding. With the purpose to save the chemical flooding costs in moderately heterogeneous reservoirs, oil recovery factors were investigated under polymer preslugs with different viscosities, subsequent displacement scheme being the same. A particular viscosity of the polymer preslug is implemented by changing the concentration of the polymer preslug while ensuring that the total amount of polymer used in the polymer preslug stage is the same. The viscosity of the polymer preslug was set at $40 \mathrm{mPa} \cdot \mathrm{s}, 60 \mathrm{mPa} \cdot \mathrm{s}$, and $80 \mathrm{mPa} \cdot \mathrm{s}$ according to the maximum operating conditions of the field injection pump system. The injection amount of each slug in the three experiment schemes was designed by maintaining the same amount of polymer in the polymer preslug in all schemes (as shown in Table 3).

The polymer preslug has a great influence on the function of ASP system. Its main function is to adjust the inner plane and longitudinal direction of the core using the viscoelasticity of polymer, reduce the heterogeneity in the reservoir, and protect the ASP main slug [32]. This helps the ASP main slug enter the oil enrichment area not affected by water flooding and reduce the adsorption loss of expensive chemical agents. The ASP main and secondary slugs can reduce the water cut of the produced fluid and increase the oil production. The concentration of chemical agents in the ASP secondary slug was lower than that in the ASP main slug [33]. At the oilfield site, it is believed that the affected area after the injection of the main slug is close to the adsorption saturation state, and the secondary slug supplements the main slug. The injection stage of ASP slug is the same as the field operation of the oilfield. The alkali, surfactant, and polymer were mixed in proportion and injected into the core. The injected chemical agent has high viscosity and can form ultralow interfacial tension with crude oil, which can extend swept volume, enhance oil displacement efficiency, and improve oil washing ratio [34]. In the ASP system, the polymer is to increase the viscosity of the system and control the fluidity, the surfactant is to reduce the oilwater interfacial tension and improve the oil washing ratio, and the alkali is to react with the acidic components of crude oil to produce surfactants in situ [35]. The subsequent polymer slug is to prevent the breakthrough of injected water in the subsequent water flooding stage from affecting the oil displacement efficiency of ASP slug and also protect the ASP slug $[1,2]$. The subsequent water flooding is to maintain the displacement pressure and reduce the agent use and cost $[3,5,7][2]$.

There is no clear standard and regulation for oil displacement experiment of large plate artificial core. The experiment refers to the Chinese small natural cylindrical core test standard GB/T 28912-2012 Test method for twophase relative permeability in rock, and the advance velocity of the displacement front is recommended as the criterion to investigate the recovery efficiency, pressure, and other parameters. According to the daily injection volume of injection wells, the spacing between production wells and production wells, and the output of production wells, the calculated thrust velocity of the mainline of the water flooding front is $1 \mathrm{~m} / \mathrm{d}$. The purpose of the experiment is to select the optimal viscosity of polymer preslug by comparison. 


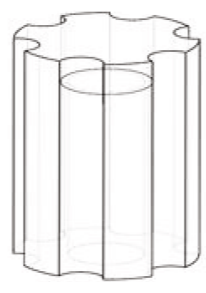

(a)

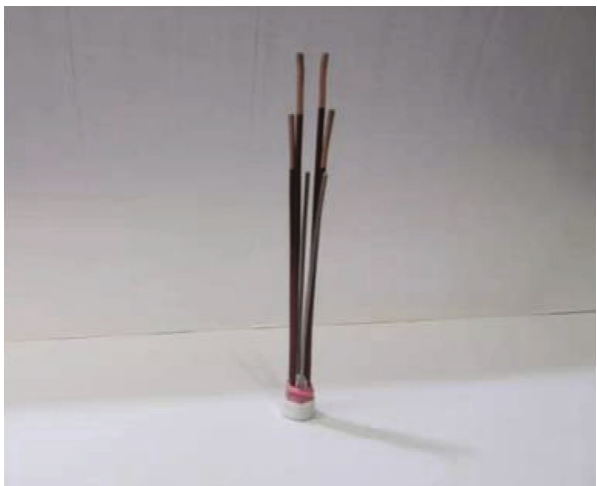

(b)

Figure 7: (a) Design drawing of electrode accessory; (b) electrode space diagram.

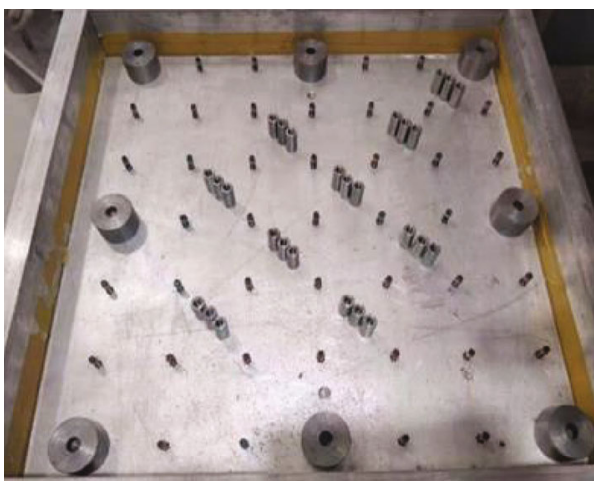

(a)

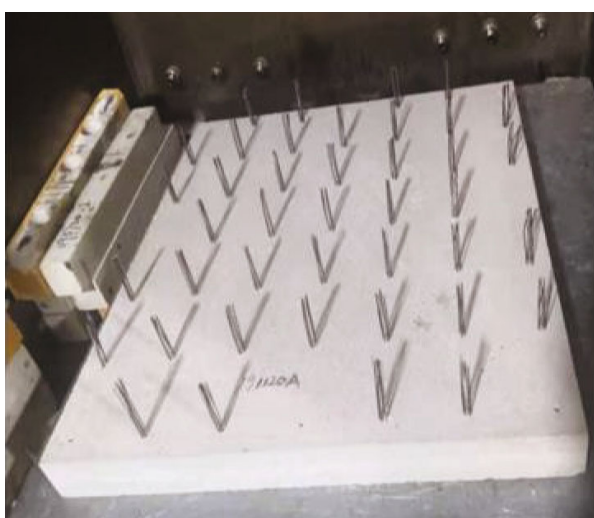

(b)

FIgURE 8: (a) Assembly of accessories; (b) the artificial sandstone core model not coated with epoxy resin.

TABLE 3: Experiment scheme for viscosity optimization of polymer preslug.

\begin{tabular}{|c|c|c|c|c|c|}
\hline Name of chemical slug & $\begin{array}{l}\text { Slug size } \\
\text { PV }\end{array}$ & $\begin{array}{c}\text { Polymer concentration } \\
\mathrm{mg} / \mathrm{L}\end{array}$ & $\begin{array}{l}\text { System viscosity } \\
\mathrm{mPa} \cdot \mathrm{s}\end{array}$ & $\begin{array}{c}\text { Alkali concentration } \\
\text { wt } \%\end{array}$ & $\begin{array}{c}\text { Surfactant concentration } \\
\text { wt } \%\end{array}$ \\
\hline \multicolumn{6}{|l|}{ Polymer preslug } \\
\hline 1 & 0.093 & 1900 & 40 & - - & - - \\
\hline 2 & 0.075 & 2360 & 60 & - - & - - \\
\hline 3 & 0.064 & 2775 & 80 & - & - - \\
\hline ASP main slug & 0.3 & 2450 & 30 & 1.2 & 0.3 \\
\hline ASP secondary slug & 0.2 & 2300 & 30 & 1.0 & 0.1 \\
\hline Subsequent polymer slug & 0.2 & 1635 & 30 & - & -- \\
\hline
\end{tabular}

TABLE 4: Simulated water ion salinity.

\begin{tabular}{lcc}
\hline No. & Agents & Mass concentration g/L \\
\hline 1 & $\mathrm{NaCl}$ & 3.977 \\
2 & $\mathrm{CaCl}_{2}$ & 0.028 \\
3 & $\mathrm{MgCl}_{2} \cdot 6 \mathrm{H}_{2} \mathrm{O}$ & 0.046 \\
4 & $\mathrm{Na}_{2} \mathrm{SO}_{4}$ & 0.093 \\
5 & $\mathrm{NaHCO}_{3}$ & 2.634 \\
& Total salinity & 6.778 \\
\hline
\end{tabular}

Therefore, the experiment mainly focuses on the changing trend of injection pressure and recovery degree and does not carry out error comparison analysis with field or other artificial cores. The experimental data in this paper are arithmetic average values of parallel experiments.

The specific steps are implemented as below: (1) the core physical model of large well group is vacuumed and saturated with simulated water; (2) the core physical model is saturated with oil with oil saturation of over $65 \%$; (3) water flooding is carried out with simulated water at a rate of $0.3 \mathrm{~mL} / \mathrm{min}$ until the water cut at the outlet stabilizes at more 


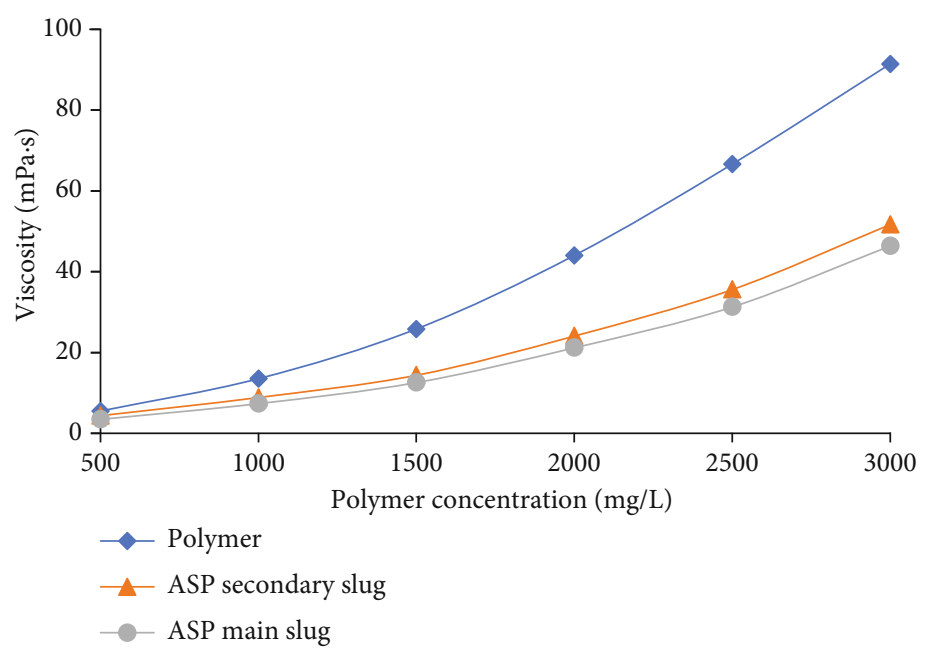

FIGURE 9: Concentration-viscosity curve of polymer.

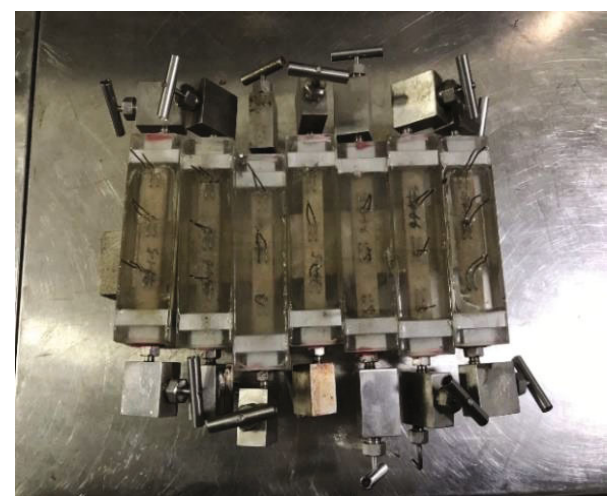

FiguRE 10: Microelectrode core model of different permeability.

than $98 \%$. It is injected into the polymer preslug, ASP main slug, ASP secondary slug, and polymer postslug; (4) subsequent water flooding is carried out until the water cut at the outlet stabilizes at more than 98\%; (5) electrodes and pressure monitoring devices are used to monitor the pressure of each layer and the distribution of remaining oil.

\section{Determination of Experimental Oil, Water, Chemical Agent, and Rock Electricity Relationship}

The oil used in the experiments was D4-1-22 wellhead crude oil from Daqing Oilfield, and the viscosity of crude oil was $10 \mathrm{mPa} \cdot \mathrm{s}$ at $45^{\circ} \mathrm{C}$. According to the ion salinity provided in the oilfield site, the simulated water was used for the preparation of saturated water, water flooding, polymer preslug, ASP main slug, ASP secondary slug, postslug, and subsequent water flooding stage of the core model of well group. The specific salinity is shown in Table 4.

In the chemical flooding agent used in the experiment, the molecular weight of the polymer was $12 \times 10^{4}$ $\sim 16 \times 10^{4} \mathrm{~g} / \mathrm{mol}$, the surfactant was petroleum sulfonate, and the alkali was analytical pure $\mathrm{Na}_{2} \mathrm{CO}_{3}$.
6.1. Determination of Polymer Viscosity-Concentration Relationship. Determination of the viscosity-concentration relationship of the polymer preslug, the ASP main slug, the ASP secondary slug, and the polymer postslug is of great significance for the precise preparation of the system viscosity in the experiment program. Polymer preslug and polymer postslug have the same composition and are collectively referred to as polymer slug in the test.

The polymer slug, ASP main slug, and ASP secondary slug with different concentrations of $500 \mathrm{mg} / \mathrm{L} \sim 3000 \mathrm{mg} / \mathrm{L}$ were prepared from the polymer mother liquid with simulated water. The viscosity of different concentrations was determined at $45^{\circ} \mathrm{C}$, and the corresponding concentration relationship curves of viscosity systems of $40 \mathrm{mPa} \cdot \mathrm{s}$, $60 \mathrm{mPa} \cdot \mathrm{s}$, and $80 \mathrm{mPa} \cdot \mathrm{s}$ were finally determined. The determined results are shown in Figure 9.

6.2. Establishment of the Relationship between Oil Saturation and Resistivity of Rock. There are two phases of oil and water in the pore medium of the core model. Anion and cation can be ionized from the salt substance in the water phase, ions will move directionally under the action of the electric field and generate current, and the current intensity is related to the content of ions in the water phase. It is assumed that other physical properties remain unchanged in the core model and that resistivity is only a function of the amount of oil and water in the pores; a standard curve of resistance values and oil saturation (water cut) can be established. The theoretical method of the relationship between Archie saturation and lithology was applied to calibrate the saturation. Since other components in the core are nonconductive, oil saturation in the core can be directly reflected by different resistance values:

$$
I=\frac{R_{t}}{R_{o}},
$$

where $R_{t}$ is the resistivity of rock containing oil, $\Omega \mathrm{m} ; R_{o}$ is the resistivity of rock completely containing water, $\Omega \mathrm{m}$. 


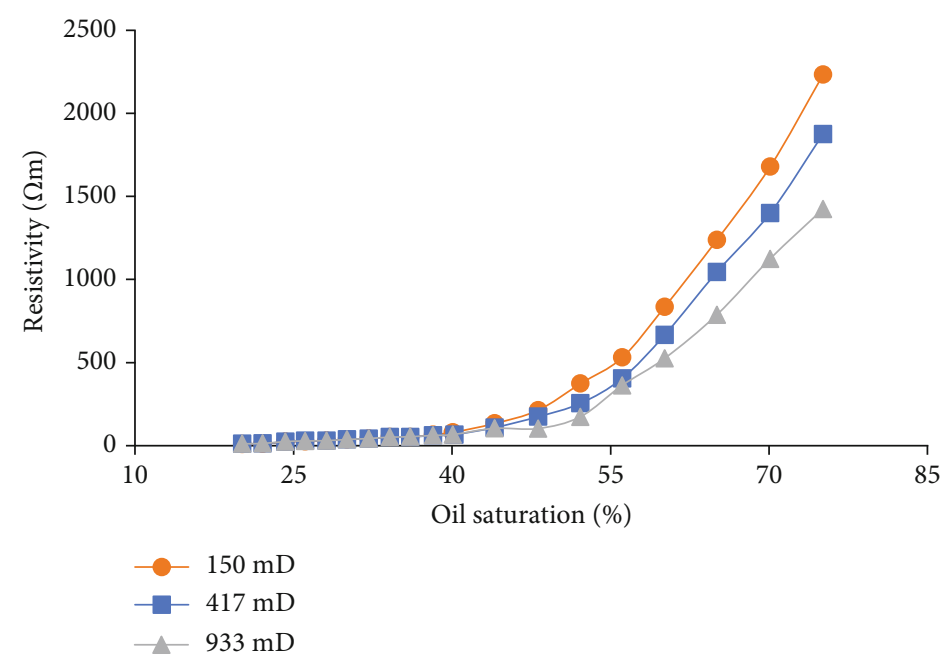

FIGURE 11: Test results of resistivity and oil saturation curves of different permeability layers.

TABLE 5: Recovery degree of different polymer preslug viscosity.

\begin{tabular}{lcccc}
\hline Scheme & $\begin{array}{c}\text { Preslug viscosity } \\
\text { mPa.s }\end{array}$ & $\begin{array}{c}\text { Recovery degree by water flooding } \\
\%\end{array}$ & $\begin{array}{c}\text { Enhancement by chemical flooding } \\
\%\end{array}$ & $\begin{array}{c}\text { Total recovery degree } \\
\%\end{array}$ \\
\hline 1 & 40 & 35.12 & 18.02 & 53.14 \\
2 & 60 & 35.44 & 19.35 & 54.79 \\
3 & 80 & 35.5 & 18.74 & 54.24 \\
\hline
\end{tabular}

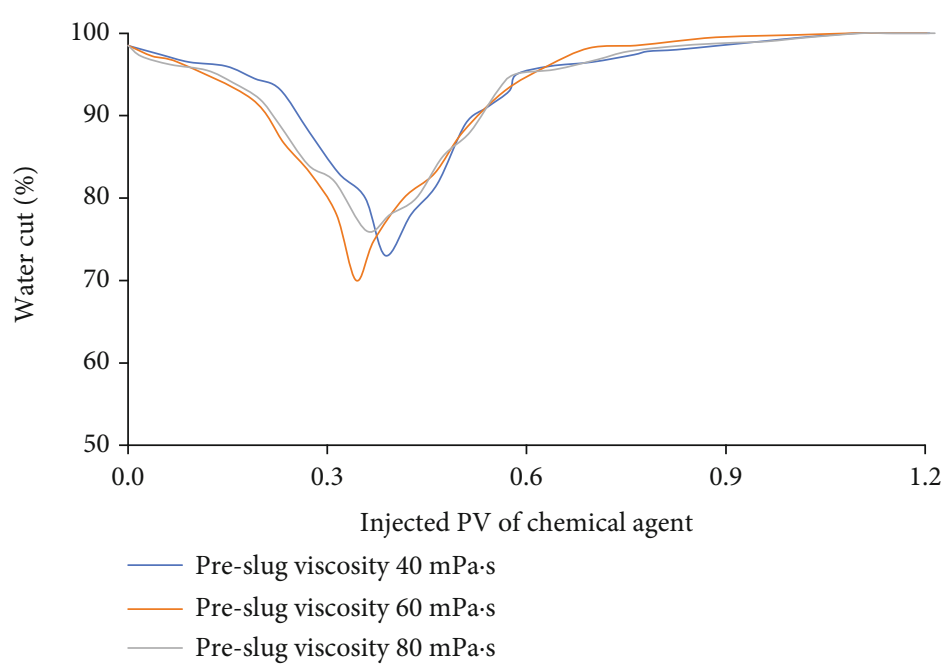

FIGURE 12: Water cut trend during chemical flooding with different polymer preslug viscosity.

The microelectrode core model with a width of $15 \mathrm{~mm}$, a height of $15 \mathrm{~mm}$, and a length of $100 \mathrm{~mm}$, as shown in Figure 10, was used to carry out the physical simulation experiment of water flooding. The microelectrode core model was used to determine the resistance values of cores with different permeability under different oil saturation, and then, the standard curve of the relationship between oil saturation and resistivity of rock was established (as shown in Figure 11). In the flooding experiment of the core model, the resistance values at different test points were monitored by a resistance recording system, and the oil saturation value of each test point can be calculated reversely according to the standard curve. Thus, the distribution of oil saturation of the whole heterogeneous well core model at any time was plotted.

\section{Experimental Results}

Table 5 shows the recovery degree of the water flooding stage and the total recovery degree of the final chemical 


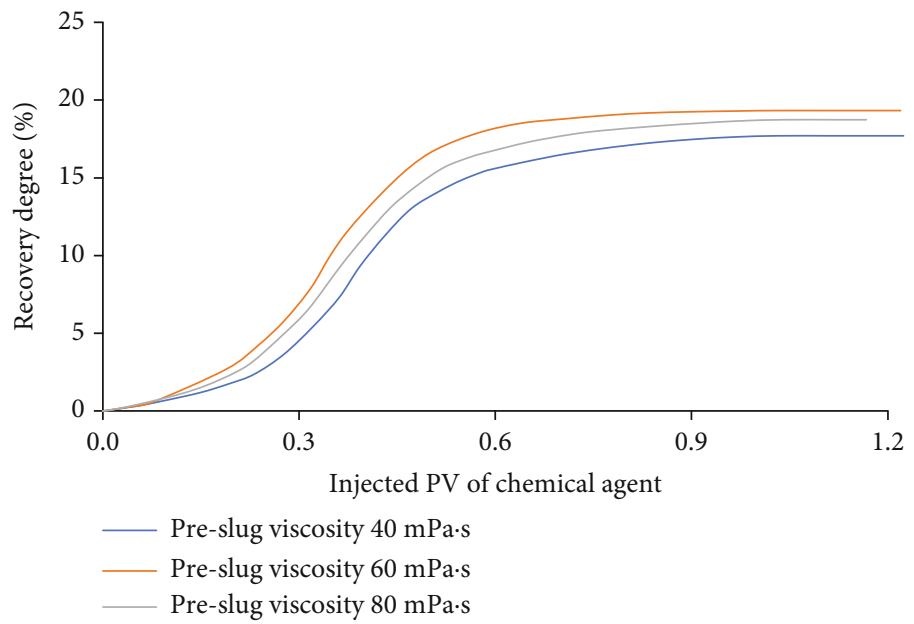

FIGURE 13: Recovery degree during chemical flooding with different polymer preslug viscosity.

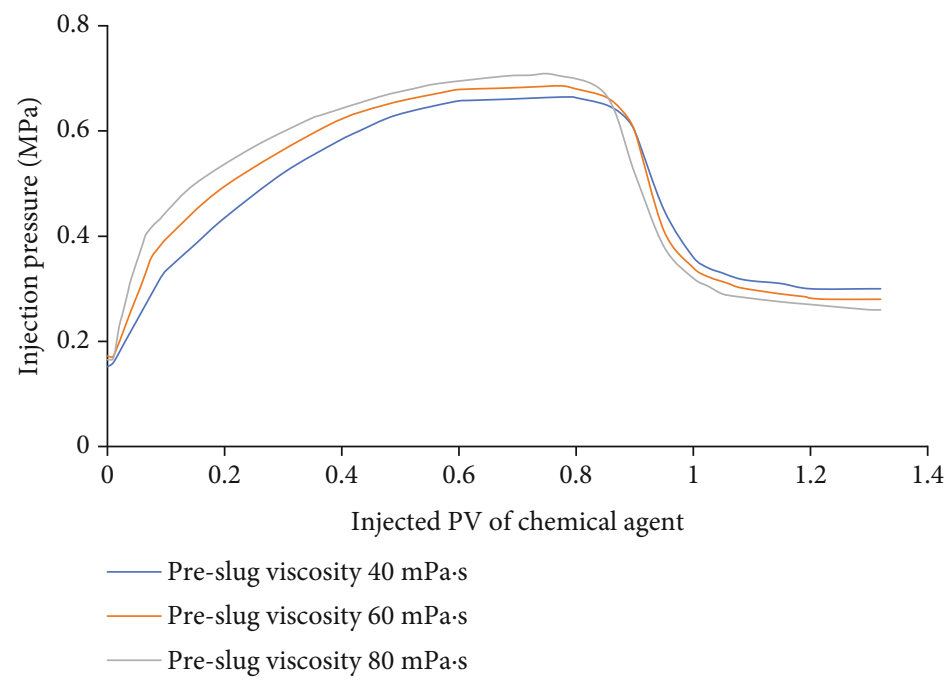

FIGURE 14: Injection pressure of different polymer preslug viscosity.

flooding in the ASP preslug experimental scheme. It is concluded that the $60 \mathrm{mPa} \cdot \mathrm{s}$ polymer preslug scheme had the best displacement effect, while the worst displacement effect was found in the $40 \mathrm{mPa}$.s polymer preslug scheme. Increasing the polymer preslug viscosity can effectively improve the recovery degree during chemical flooding, which does not mean that the higher the viscosity the better, for example, the $80 \mathrm{mPa} \cdot \mathrm{s}$ polymer preslug scheme had a weaker oil displacement effect than the $60 \mathrm{mPa} \cdot \mathrm{s}$ polymer preslug scheme.

Taking the end of water flooding as the monitoring starting point, the relationship curve between the injected PV of chemical agent and the water cut at the core outlet was plotted (as shown in Figure 12). At the initial stage of chemical flooding (0-0.31 PV), the water cut of the $60 \mathrm{mPa} \cdot \mathrm{s}$ polymer preslug system decreased rapidly, proving that the $60 \mathrm{mPa} \cdot \mathrm{s}$ system has more prominent advantages in profile control by chemical flooding, which allows for earlier water injection effect of the ASP main slug. In the middle stage of chemical flooding (0.31-0.51 PV), the water cut recovered slowly, which proved the full water injection effect of main and secondary slugs. Under the experimental conditions, the improvement by chemical flooding in the $60 \mathrm{mPa} \cdot \mathrm{s}$ system was $1.33 \%$ and $0.6 \%$ higher than the $40 \mathrm{mPa} \cdot \mathrm{s}$ and $80 \mathrm{mPa} \cdot \mathrm{s}$ systems, respectively.

The polymer preslug chemical flooding scheme of three viscosity systems had a stable oil production time (as shown in Figure 13). The $60 \mathrm{mPa} \cdot \mathrm{s}$ system showed good oil recovery effect from the initial stage of chemical flooding, indicating that the $60 \mathrm{mPa} \cdot \mathrm{s}$ system has a good match with the reservoir with a coefficient of variation of 0.65 .

7.1. Pressure Change. Increasing the viscosity of the polymer preslug can increase the injection-production pressure difference. However, the high viscosity of the system will result in pressure concentration near the injection well, and the area near the well has large pressure loss, short pressure propagation distance, and small spreading range. Pressure 


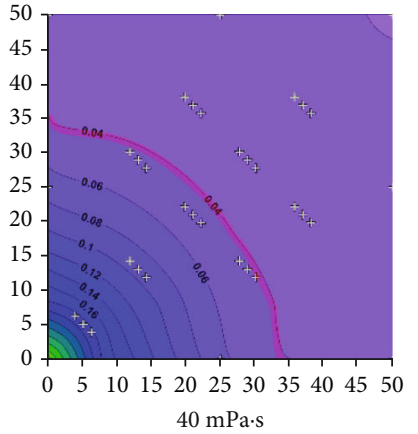

$40 \mathrm{mPa} \cdot \mathrm{s}$

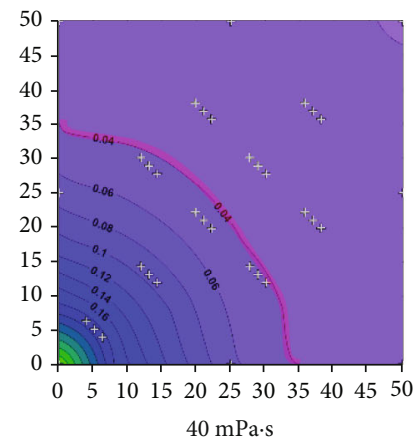

$40 \mathrm{mPa} \cdot \mathrm{s}$

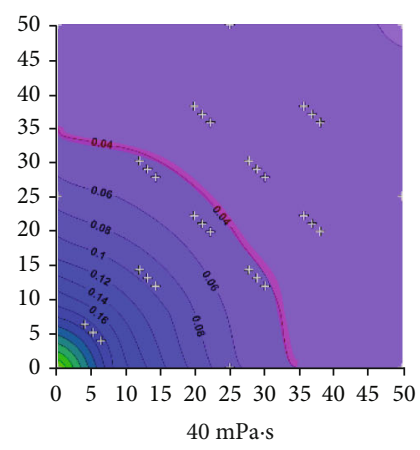

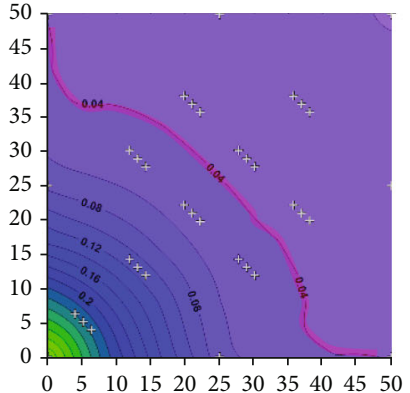

$60 \mathrm{mPa} \cdot \mathrm{s}$

(a)

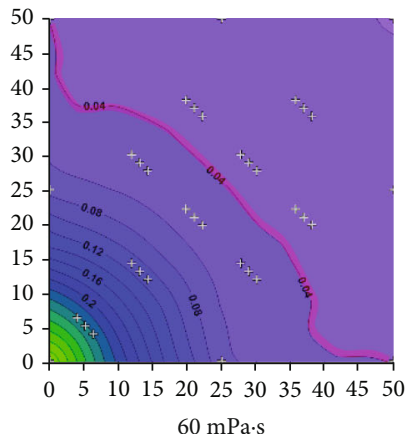

(b)

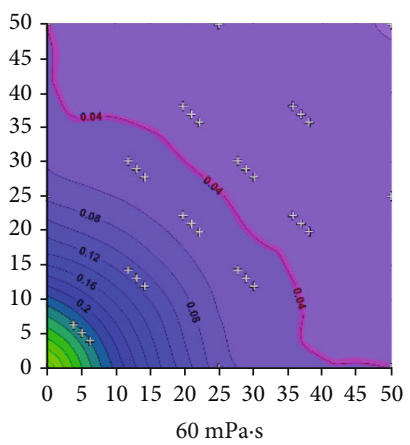

(c)
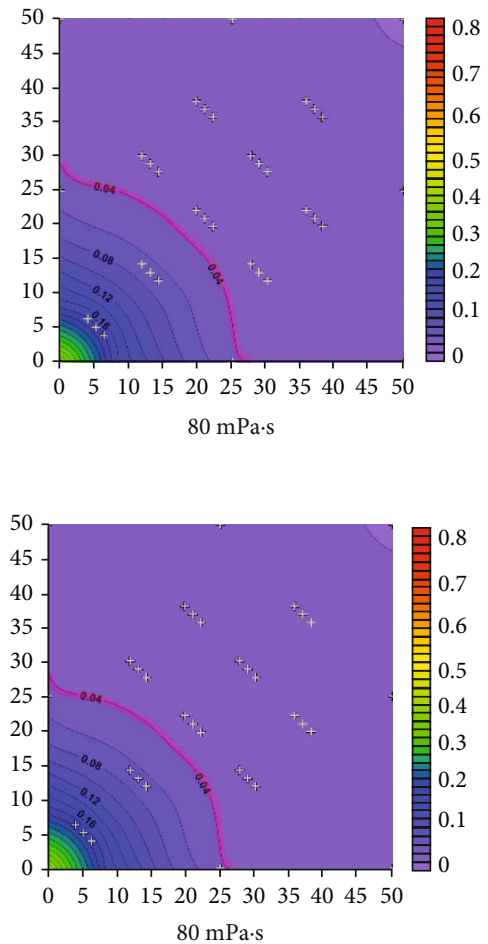

$80 \mathrm{mPa} \cdot \mathrm{s}$

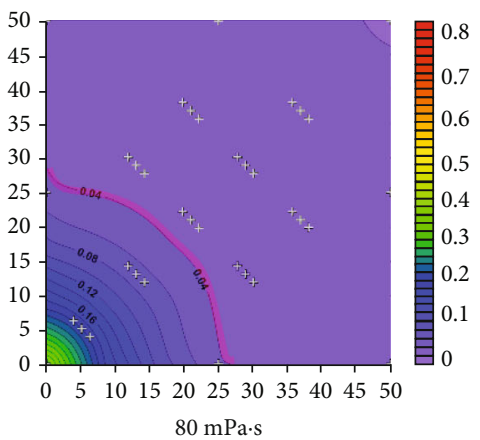

Figure 15: Pressure field distribution at the end of the ASP main slug stage under different polymer preslug viscosity; (a) pressure field distribution in low-permeability layer; (b) pressure field distribution in medium-permeability layer; (c) pressure field distribution in high-permeability layer.

changes during the chemical flooding are shown in Figure 14.

High-viscosity polymer will lead to increased injection pressure, the polymer accumulates at the injection end, and the viscosity decreases due to severe shear, resulting in serious displacement pressure loss, which exhibits a small pressure sweep area in the core. According to the pressure monitoring data, the pressure field diagram of each layer at the end of the ASP main slug stage was plotted (as shown in Figure 15). There was no obvious difference in the pressure sweep range of displacement fluid in reservoirs with different permeability, and the pressure and sweep range of each layer were close $[36,37]$. However, the stress condition in the core matrix was obviously different according to poroelasticity or thermo-poroelasticity theory [38, 39]. It is planned in the next phase of the project, with additional experimental modules to be added, it will be possible to monitor the changes of stress in the matrix.

7.2. Remaining Oil Distribution. At the end of the ASP main slug stage, the remaining oil distribution of each permeability layer in the core physical model of well group is shown in Figure 16. Increasing the viscosity of the polymer preslug is beneficial for the ASP system to expand along the diagonal main stream line to the sides rich in remaining oil in the high-permeability layer, the producing degree of the medium-permeability layer significantly increases, and significant producing effect appears near the injection well in the low-permeability layer. If the polymer preslug system has very high viscosity, the profile control system will have similar longitudinal and lateral advance effect as the lowviscosity system, and the difference of remaining oil 


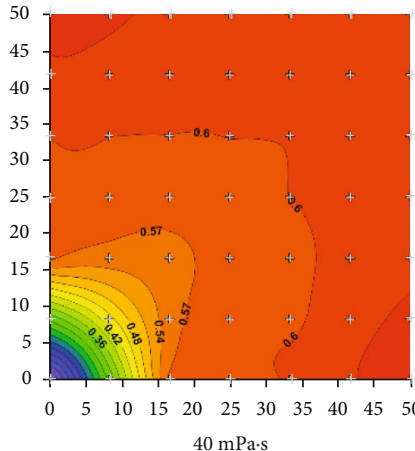

$40 \mathrm{mPa} \cdot \mathrm{s}$

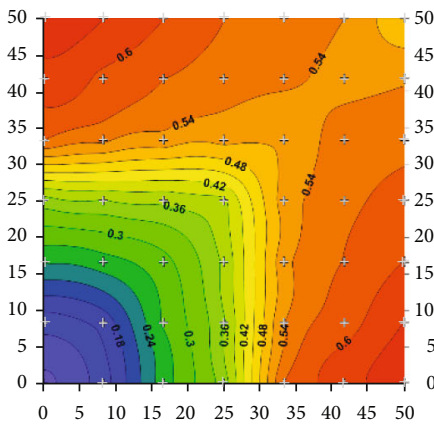

$40 \mathrm{mPa} \cdot \mathrm{s}$
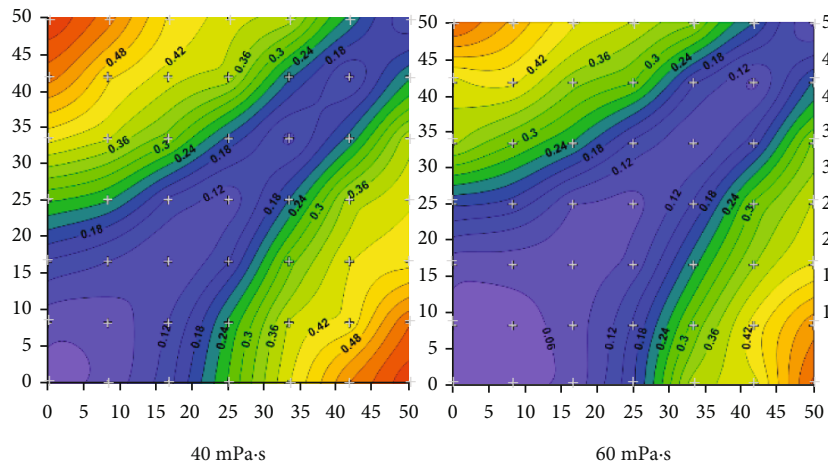

$60 \mathrm{mPa} \cdot \mathrm{s}$

(c)

(a)

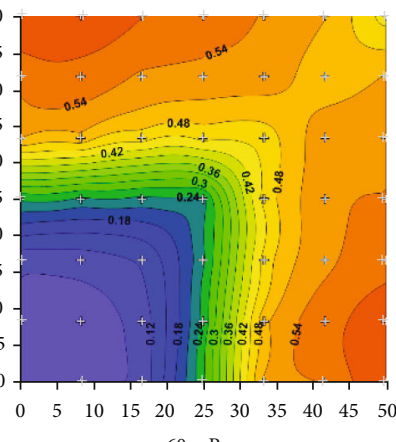

(b)
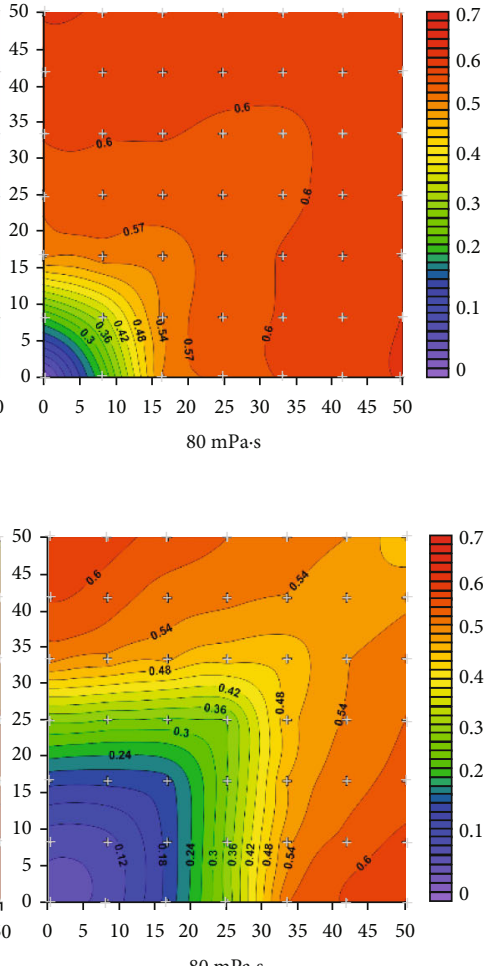

FIgURE 16: Remaining oil distribution at the end of the ASP main slug stage under different polymer preslug viscosity; (a) remaining oil distribution in low-permeability layer; (b) remaining oil distribution in medium-permeability layer; (c) remaining oil distribution in high-permeability layer.

production between layers is quite significant after the ASP main slug flooding.

According to the electrode test resistance, the oil saturation distribution of the longitudinal profile along the diagonal direction of the core, namely, the direction of the main stream line, was plotted (as shown in Figure 17). The $40 \mathrm{mPa} \cdot \mathrm{s}$ polymer preslug chemical flooding system did not improve the displacement profile vertically. Due to the low viscosity and small displacement differential pressure increment, the displacement fluid only improved the displacement channel after water flooding in the high-permeability layer. Due to the large injection pressure difference of $80 \mathrm{mPa} \cdot \mathrm{s}$ polymer preslug chemical flooding system, the displacement fluid did not exhibit a good elastic displacement relationship with the reservoir. In the middle area of the injection well and the production well, the displacement fluid did not diffuse in the upper medium-permeability layer and low-permeability layer, but flew to the bottom of production well along the bottom of high-permeability layer. This also shows that the high-viscosity polymer preslug has a better profile-control effect for wells close to each other. With high injection pressure, the polymer will suffer severe shear and high viscosity loss in the reservoir, and the chemical flooding system cannot maintain effective viscosity.

Different from the pressure distribution field, the distribution of oil saturation field is quite different in different permeability layers, which can effectively determine the production degree of ASP chemical flooding. The remaining oil 


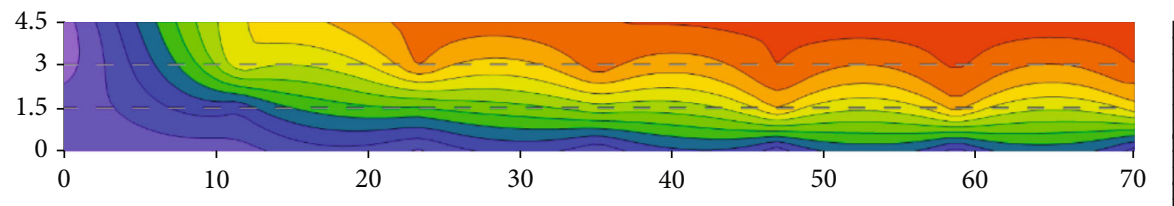

(a)

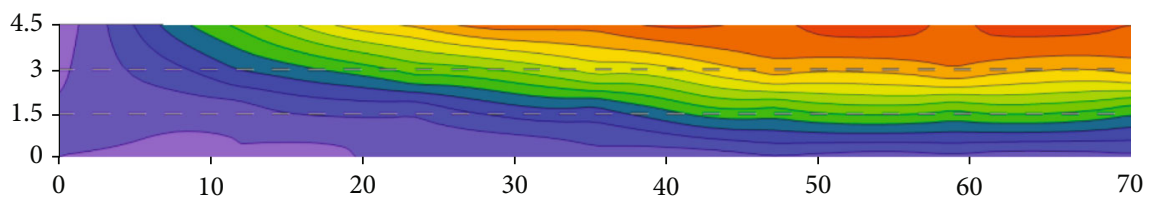

(b)
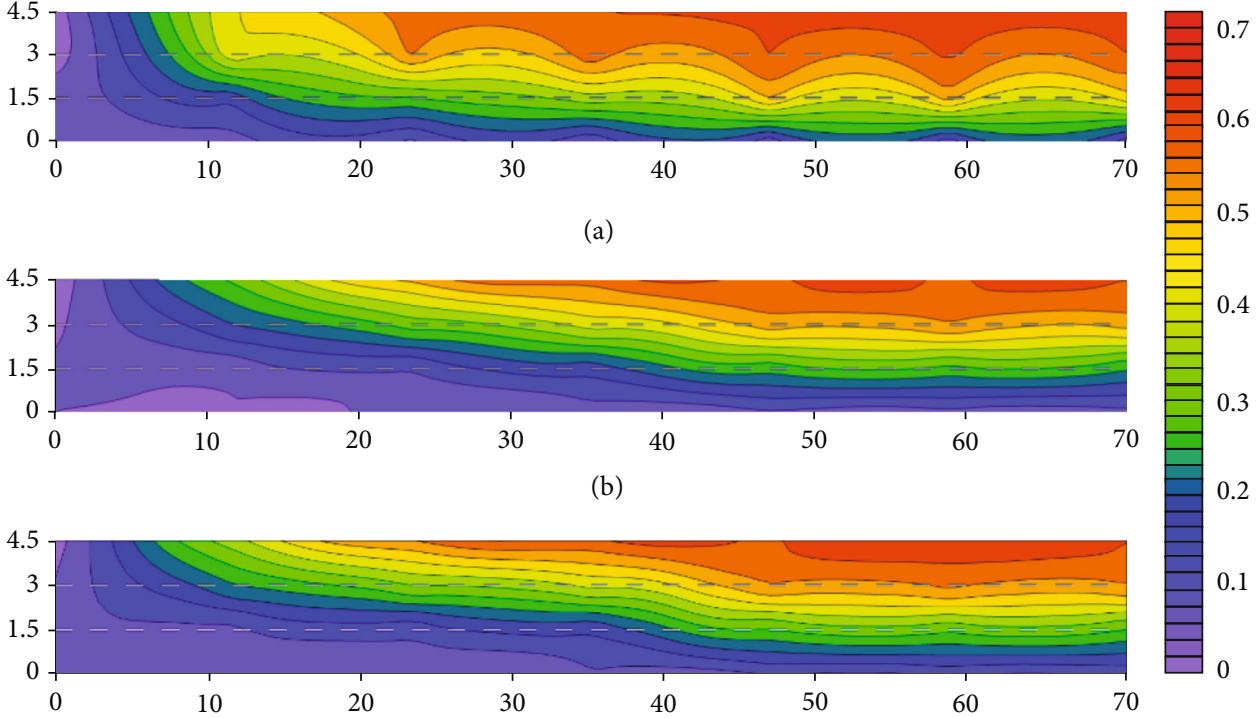

(c)

FIGURE 17: Distribution profile of residual oil along main stream line at the end of the ASP main slug stage under different polymer preslug viscosity, (a) the polymer preslug viscosity is $40 \mathrm{mPa} \cdot \mathrm{s}$; (b) the polymer preslug viscosity is $60 \mathrm{mPa} \cdot \mathrm{s}$; (c) the polymer preslug viscosity is $80 \mathrm{mPa} \cdot \mathrm{s}$.

in the high-permeability layer was more thoroughly exploited, with oil saturation as low as $12 \%$ in the main stream line and an average oil saturation of about $27 \%$. At the bottom of the medium-permeability layer, the main stream line runs through injection and production wells, while no obvious main producing area running through injection and production wells was found in the lowpermeability layer. This indicates that the main increased oil production area of the ASP system comes from the lateral profile control in the high-permeability layer, and a small part comes from the near-wellbore area of the injection well and the main stream line area at the bottom of the mediumpermeability layer. The low-permeability reservoir had a very limited producing effect, and the change in the viscosity of the polymer preslug had an obvious effect on the profilecontrol of medium- and high-permeability layers for moderately developed heterogeneous reservoirs. Therefore, the injectability of polymer preslug and the effect of alleviating interlayer conflicts are related to the viscosity of chemical flooding system, so the viscosity of polymer preslug shall not be too high, and cores with different heterogeneity should have a reasonable viscosity matching range.

\section{Conclusions}

In this paper, economical use of the ASP is investigated. Preslug is beneficial, and the viscosity of polymer preslug shall not be too high. Higher viscosity will lead to increased injection pressure, ineffective elastic displacement of polymer and ASP chemical flooding systems, and fast viscosity loss of the injected displacement fluid, resulting in the waste of chemical agents. The reasonable polymer preslug viscosity is $60 \mathrm{mPa} \cdot \mathrm{s}$ in a heterogeneous reservoir with a coefficient of variation of 0.65 .
Under the same pressure field, remaining oil distribution, recovery degree, and chemical agent dosage, the polymer preslug with viscosity of $60 \mathrm{mPa} \cdot \mathrm{s}$ and slug size of $0.075 \mathrm{PV}$ are more beneficial for the pressure to extend to the nonmain stream line area on both sides and tend to increase the sweep area of the plane. Longitudinally near the injection well, the production conflict between mediumand high-permeability layers can be alleviated, which effectively improves the degree of production at the bottom of the high-permeability and the medium-permeability layers, as well as the injection end of the medium-permeability layer.

The remaining oil in the low-permeability layer cannot be effectively displaced by changing the viscosity of the polymer preslug in the ASP chemical flooding system. The major areas of increased oil production at the ASP flooding stage are the high-permeability layer and the bottom of medium-permeability layer.

The making process of core physical model of large well group was explored and improved, the pressing mold and accessories were designed, and the arrangement of water cut monitoring electrode was optimized. Moreover, the process of drilling pressure holes and injection/production holes after core cementation was avoided, which ensures that the physical parameters of core after cementation were not affected by the installation of accessories. It can satisfy the high-pressure requirements of chemical flooding experiments and accurately detect water cut and pressure changes in the core.

After ASP flooding, thick reservoirs are mostly exploited by subsequent water flooding to maintain formation pressure, but the subsequent development effect is staggeringly inefficient. At present, both laboratory and field experiments show that the recovery degree of low- and medium- 
permeability reservoirs after ASP flooding is low, and it has great potential for further tapping the remaining oil of lowand medium-permeability reservoirs by fracturing technology [40]. In laboratory experiments, the large size of the core can be complete debonding or no water cut, can capture area of low- and medium-permeability core samples for triaxial fracturing experiment, which can be used to investigate the enhanced oil recovery range of the ternary system after fracturing, and can also be compared with the triaxial fracturing of the core sample of the low- and medium-permeability reservoir after water flooding to investigate the fracturing effect of the ternary system after flooding $[41,42]$.

\section{Data Availability}

All data used can be found in our manuscript.

\section{Conflicts of Interest}

The authors declare no conflicts of interest.

\section{Acknowledgments}

This research was funded by the Natural Science Foundation of Heilongjiang Province, grant number LH2019E017.

\section{References}

[1] G. Shutang and G. Qiang, "Recent progress and evaluation of ASP flooding for EOR in Daqing oil field," in SPE EOR Conference at Oil \& Gas West Asia, pp. 1-7, Muscat, Oman, 2010.

[2] J. Cheng, G. Liao, Z. Yang, L. I. Qun, Y. Yao, and X. U. Dian, "Pilot test of asp flooding in Daqing oilfield," in Petroleum Geology \& Oilfield Deuelopment, vol. 20no. 2, pp. 46-49, Daqing, 2001.

[3] M. Ajay, "Chemical flood enhanced oil recovery: a review," International Journal of Oil Gas \& Coal Technology, vol. 9, no. 3, p. 241, 2015.

[4] B. Dehdari, R. Parsaei, M. Riazi, N. Rezaei, and S. Zendehboudi, "New insight into foam stability enhancement mechanism, using polyvinyl alcohol (PVA) and nanoparticles," Journal of Molecular Liquids, vol. 307, article 112755, 2020.

[5] A. A. Adasani and B. Bai, "Analysis of EOR projects and updated screening criteria," Journal of Petroleum Science \& Engineering, vol. 79, no. 1-2, pp. 10-24, 2011.

[6] P. J. Liyanage, S. Solairaj, G. W. Arachchilage et al., "Alkaline surfactant polymer flooding using a novel class of large hydrophobe surfactants," in SPE Improved Oil Recovery Symposium, pp. 14-18, Tulsa Oklahoma USA, April 2012.

[7] O. Mohammadzadeh, M. H. Sedaghat, S. Kord, S. Zendehboudi, and J. P. Giesy, "Pore-level visual analysis of heavy oil recovery using chemical-assisted waterflooding process - use of a new chemical agent," Fuel, vol. 239, pp. 202218, 2019.

[8] H. Guo, Y. Li, F. Wang et al., "ASP flooding: theory and practice progress in China," Journal of Chemistry, vol. 2017, Article ID 8509563, 18 pages, 2017.

[9] M. Algharaib, A. Alajmi, and R. Gharbi, "Improving polymer flood performance in high salinity reservoirs," Journal of Petroleum Science and Engineering, vol. 115, pp. 17-23, 2014.
[10] W. Demin, Z. Zhenhua, C. Jiecheng, Y. Jingchun, G. Shutang, and L. Li, "Pilot test of alkaline surfactant polymer flooding in Daqing oil field," SPE Reservoir Engineering, vol. 12, no. 4, pp. 229-233, 1997.

[11] B. Huang, W. Zhang, H. Liu, C. Fu, P. Feng, and Y. Wang, "A study on the optimization of surfactants in the main and vice slug in weak base ASP flooding," Energies, vol. 10, no. 3, p. 304, 2017.

[12] J. Hu, A. Li, and A. Memon, "Experimental investigation of polymer enhanced oil recovery under different injection modes," ACS Omega, vol. 5, no. 48, pp. 31069-31075, 2020.

[13] M. Y. Khan, A. Samanta, K. Ojha, and A. Mandal, "Design of alkaline/surfactant/polymer (ASP) slug and its use in enhanced oil recovery," Petroleum Science and Technology, vol. 27, no. 17, pp. 1926-1942, 2009.

[14] J. B. Lawson and J. Reisberg, "Alternate slugs of gas and dilute surfactant for mobility control during chemical flooding SPE/DOE enhanced oil recovery symposium," Society of Petroleum Engineers, vol. 4, pp. 289-295, 1980.

[15] S. S. Riswati, W. Bae, C. Park, A. K. Permadi, I. Efriza, and B. Min, "Experimental analysis to design optimum phase type and salinity gradient of alkaline surfactant polymer flooding at low saline reservoir," Journal of Petroleum Science and Engineering, vol. 173, pp. 1005-1019, 2019.

[16] D. Yin, S. Song, Q. Xu, and K. Liu, "Experimental research on the optimization and evaluation of the polymer/chromiumion deep profile control system for the fractured lowpermeability reservoirs," Processes, vol. 8, no. 9, article 1021, 2020.

[17] X. Nie, J. Chen, Y. Cao et al., "Investigation on plugging and profile control of polymer microspheres as a displacement fluid in enhanced oil recovery," Polymers, vol. 11, no. 12, p. 1993, 2019.

[18] J. J. Sheng, "A comprehensive review of alkaline-surfactantpolymer (ASP) flooding," Journal of Chemical Engineering, vol. 9, no. 4, pp. 471-489, 2014.

[19] J. Hou, S. Zhang, M. Dong, X. Yue, and J. Yang, "Effect of viscosity of alkaline/surfactant/polymer (ASP) solution on enhanced oil recovery in heterogeneous reservoirs," in Canadian International Petroleum Conference, vol. 45, pp. 27-33, Calgary, Alberta, 2006.

[20] S. A. Shedid, "Experimental investigation of alkaline/surfactant/polymer (ASP) flooding in low permeability heterogeneous carbonate reservoirs," in SPE North Africa Technical Conference and Exhibition, Cairo, Egypt, 2015.

[21] B. Huang, X. Hu, C. Fu, and L. Wang, "Experimental evaluation of ASP flooding to improve oil recovery in heterogeneous reservoirs by layered injection approach," Energy Science of Engineering, vol. 8, no. 9, pp. 3148-3164, 2020.

[22] X. Sui, Z. Chen, I. Kurnia, X. Han, J. Yu, and G. Zhang, “Alkaline-surfactant-polymer flooding of active oil under reservoir conditions," Fuel, vol. 262, article 116647, 2020.

[23] Y. Li, M. Long, L. Zuo, W. Li, and W. Zhao, "Brittleness evaluation of coal based on statistical damage and energy evolution theory," Journal of Petroleum Science and Engineering, vol. 172, pp. 753-763, 2019.

[24] J. J. Li, H. Q. Jiang, J. R. Hou, X. Wang, and L. Su, “The effects of oil displacement efficiency and conformance efficiency on viscosity of asp flooding in a heterogeneous reservoir," Journal of Natural Gas Science and Engineering, vol. 32, no. 7, pp. 830839, 2014. 
[25] Q. Sun, C. Wang, X. Wang, and B. Dong, "Development of a new high-temperature-resistant plugging agent for heavy oil recovery by steam flooding of resevoirs," Chemistry and Technology of Fuels and Oils, vol. 52, no. 4, pp. 462-468, 2016.

[26] Z. Liu, S. Wang, H. Ye et al., "Experimental study on the effects of pre-cracks fracturing fluid and rock mechanical characteristics on directional hydraulic fracturing with axial pre-cracks," Geomechanics and Geophysics for Geo-Energy and GeoResources, vol. 7, no. 2, p. 29, 2021.

[27] A. A. Olajire, "Review of ASP EOR (alkaline surfactant polymer enhanced oil recovery) technology in the petroleum industry: prospects and challenges," Energy, vol. 77, pp. 963982, 2014.

[28] Z. Fengshou, A. Mengke, Z. Lianyang, F. Yi, and E. Derek, "Effect of mineralogy on friction-dilation relationships for simulated faults: implications for permeability evolution in caprock faults," Geoscience Frontiers, vol. 11, no. 2, pp. 439450, 2020.

[29] L. Zhenghe, R. Xiaokai, L. Xiao, L. Haojie, Y. Lusheng, and Y. Jianfeng, "Effects of confining stresses pre-crack inclination angles and injection rates: observations from large-scale true triaxial and hydraulic fracturing tests in laboratory," Rock Mechanics and Rock Engineering, vol. 53, no. 4, pp. 19912000, 2020.

[30] K. Panthi, H. Sharma, and K. K. Mohanty, "ASP flood of a viscous oil in a carbonate rock,” Fuel, vol. 164, pp. 18-27, 2016.

[31] L. Yuwei, L. Min, T. Jizhou, C. Mian, and F. Xiaofei, “A hydraulic fracture height mathematical model considering the influence of plastic region at fracture tip," Petroleum Exploration and Development, vol. 47, no. 1, pp. 184-195, 2020.

[32] A. Kumar and A. Mandal, "Core-scale modelling and numerical simulation of zwitterionic surfactant flooding: designing of chemical slug for enhanced oil recovery," Journal of Petroleum Science and Engineering, vol. 192, article 107333, 2020.

[33] L. Daoshan, L. Shouliang, L. Yi, and W. Demin, "The effect of biosurfactant on the interfacial tension and adsorption loss of surfactant in ASP flooding," Colloids and Surfaces A: Physicochemical and Engineering Aspects, vol. 244, no. 1-3, pp. 5360, 2004

[34] J. J. Sheng, "Investigation of alkaline-crude oil reaction," Petroleum, vol. 1, no. 1, pp. 31-39, 2015.

[35] S. Gao, Y. He, Y. Zhu, P. Han, S. Peng, and X. Liu, “Associated polymer ASP flooding scheme optimization design and field test after polymer flooding in Daqing oilfield," in SPE Improved Oil Recovery Conference, Virtual, 2020.

[36] Q. Sun, H. Li, Y. Xu, and X. Zhao, "The research of vapor phase front migration rules in steam assisted gravity drainage," The International Journal of Multiphysics, vol. 14, no. 4, pp. 359-371, 2020.

[37] S. Yin, M. B. Dusseault, and L. Rothenburg, "Thermal reservoir modeling in petroleum geomechanics," International Journal for Numerical and Analytical Methods in Geomechanics, vol. 33, no. 4, pp. 449-485, 2009.

[38] S. Yin, "Numerical analysis of thermal fracturing in subsurface cold water injection by finite element methods," International Journal for Numerical and Analytical Methods in Geomechanics, vol. 37, no. 15, pp. 2523-2538, 2013.

[39] S. Yin, "A fully coupled finite element framework for thermal fracturing simulation in subsurface cold $\mathrm{CO}_{2}$ injection," Petroleum, vol. 4, no. 1, pp. 65-74, 2018.
[40] Z. Cong, Y. Li, Y. Pan et al., "Study on $\mathrm{CO}_{2}$ foam fracturing model and fracture propagation simulation," Energy, vol. 238, p. 121778, 2021.

[41] N. Y. Erik and A. Faruk, "Use of petrological and organic geochemical data in determining hydrocarbon generation potential of coals: Miocene coals of Malatya Basin (Eastern Anatolia-Turkey)," International Journal of Coal Science \& Technology, 2021.

[42] L. Yuwei, J. Dan, R. Zhenhua, P. Jiyong, F. Chunkai, and Z. Jun, "Evaluation method of rock brittleness based on statistical constitutive relations for rock damage," Journal of Petroleum Science and Engineering, vol. 153, pp. 123-132, 2017. 